\title{
Microfluidic profiling of apoptosis-related genes after treatment with BH3-mimetic agents in astrocyte and glioblastoma cell lines
}

\author{
EVA VIDOMANOVA ${ }^{1}$, PETER RACAY $^{1,2}$, IVANA PILCHOVA ${ }^{1}$, ERIKA HALASOVA ${ }^{1,3}$ and JOZEF HATOK ${ }^{1,2}$ \\ ${ }^{1}$ Biomedical Center Martin, Jessenius Faculty of Medicine in Martin, Comenius University in Bratislava (JFM CU); \\ Departments of ${ }^{2}$ Medical Biochemistry and ${ }^{3}$ Medical Biology, Jessenius Faculty of Medicine in Martin, \\ Comenius University in Bratislava (JFM CU), SK-03601 Martin, Slovakia
}

Received June 1, 2016; Accepted July 17, 2016

DOI: $10.3892 /$ or.2016.5191

\begin{abstract}
Glioblastoma (GB) is the most frequent and biologically the most aggressive primary brain tumor in adults. Standard treatment for newly diagnosed GB consists of surgical resection, radiotherapy and chemotherapy. Resistance to therapy is a major obstacle, even with optimal treatment with a survival median of only 12-15 months. The heterogeneity and treatment response of GB makes this tumor type a challenging area of research. The aim of our study was to study the response of normal human astrocyte (HA) and human GB (T98G) cell lines to apoptosis inhibitors in vitro. ABT-737 is an inhibitor of anti-apoptotic proteins Bcl-2, Bcl-xL, Bcl-w, while MIM-1 is an Mcl-1 protein inhibitor. The viability of the cells was assayed biochemically using the cytotoxic methyl thiazolyl tetrazolium (MTT) assay. Changes in the expression of apoptosis-associated genes $(n=93)$ in two human brain cell lines after treatment with the apoptosis inhibitors ABT-737 and MIM-1 (individually), between the apoptosis inhibitor treated group and the control group, were determined using a commercially pre-designed microfluidic array. Significant changes in apoptotic gene expression with more than a 2.0-fold difference in their expression levels were obtained in both cell lines; the most altered genes were in the HA cell line after MIM-1 treatment $(n=42)$. These results contribute to the importance of apoptosis in normal and cancerous brain tissues and provide information on the effect of apoptosis inhibitors on cell viability and gene expression. Despite extensive investigations, a cure for GB is currently not available. The identification of an apoptotic gene panel and determining the sensitivity of normal and GB brain cells to individual apoptosis inhibitors could help to improve clinical practice and
\end{abstract}

Correspondence to: Dr Jozef Hatok, Department of Medical Biochemistry, Jessenius Faculty of Medicine in Martin, Comenius University in Bratislava, Mala Hora 11161/4D, SK-03601 Martin, Slovakia

E-mail: hatok@jfmed.uniba.sk

Key words: apoptosis, brain tumor, glioblastoma multiforme, astrocytes, gene expression increase our understanding of brain tumor cell metabolism and apoptosis inhibitors in GB cells and astrocytes. Recognizing expression changes in pro-apoptotic and anti-apoptotic genes could contribute to the development of new treatments.

\section{Introduction}

Uncontrolled cell proliferation, disorganized tissue growth and subsequent tumor formation may be the result of dysregulation in cell growth and antigrowth signals and changes in programmed cell death pathways. The aberrant expression of multiple genes makes normal cells ignore growth controlling signals, resulting in tumor formation. Tumors of the central nervous system (CNS) are characterized by heterogeneity within the cell population and represent a very serious medical problem $(1,2)$. The grading system of brain tumors according to World Health Organization (WHO) assigns grades I-IV in order of increasing anaplasia and malignancy. Brain tumors with a low growth rate have a benign character (WHO grade I or II) while tumors with malignant character (WHO grade III or IV) can infiltrate into surrounding tissue (3). The incidence of primary malignant brain and CNS cancer in developed countries is 5.8 per 100,000 in males and 4.4 per 100,000 in females (4).

Gliomas originate from dedifferentiated mature neural cells that may transform into cancer stem cells (CSCs) $(2,5)$. For treatment to be successful, it is crucial to eliminate CSCs, which represent a key factor in tumor reduction $(6,7)$. According to the WHO classification system established in 2007, glioblastoma (GB) is the most aggressive WHO grade IV astrocytoma (3) and is the most frequent histological type of brain tumor, accounting for $60-70 \%$ of all gliomas $(8,9)$. The prognosis remains very poor, with most patients dying within one year of diagnosis. GB affects patients of different ages and develops through different genetic pathways (10). Despite the immense pace of research to increase our understanding of the molecular basis of GB, the clinical utility of key genes and markers remains limited (11).

The majority of GBs arise de novo from astrocytes and are designated primary GB, and are found mostly in older patients. On the contrary, secondary GBs develop via malignant transformation of lower grade astrocytomas and are more often observed in younger patients $(4,5,8,12)$. The mean age 
of primary GB patients is $55-62$ years, with a median survival of 4.7 months, while secondary GB patients have a mean age 40-45 years, with a significantly longer median survival of 7.8 months $(10,13)$. Standard treatment for patients with newly diagnosed GB consists of surgical resection, radiotherapy and chemotherapy. Despite considerable progress in research, the survival rate of GB patients has not improved as expected and resistance to clinical therapy is a major obstacle to successful treatment $(7,14)$. Radiotherapy and chemotherapy work predominantly by inducing apoptosis (15). The unfavorable prognosis of patients diagnosed with GB can also be explained by our poor understanding of GB molecular pathway alterations. The elucidation of disturbances present in apoptotic pathways is one way to avoid GB resistance to therapy $(14,16)$. Dysregulation of physiological apoptosis mechanisms plays an important role in the pathogenesis and progression of gliomas.

Difficult access to human tumors and normal brain tissue makes commercially available cell lines useful and popular experimental models. Therefore, the characterization of their features and response to a wide range of agents can provide important information and knowledge. The majority of spontaneous cell deaths in malignant gliomas are due to apoptosis $(9,17,18)$. Resistance to apoptosis is a common feature of tumor cells and leads to drug resistance mediated by the $\mathrm{Bcl}-2$ family of proteins (19).

Activation of apoptosis can be triggered by different pathways distinguished according to pathological conditions in a specific tissue type. Understanding the mechanisms involved in apoptotic signaling pathways in GB may contribute to identifying target molecules for molecular therapies (20). The two main apoptotic pathway types have been classified depending on the origin of the stimulus of death: (i) the extrinsic receptor pathway and (ii) the intrinsic mitochondrial pathway $(21,22)$. The final step in both pathways, which leads to programmed cell death, is the activation of effector caspases (23). The extrinsic apoptotic pathway is activated by the stimulation of tumor necrosis factor (TNF)- $\alpha$ or Fas cell surface death receptors. The TNF family and its corresponding receptors play important roles in cell death or survival, proliferation and maturation. All members of the TNF superfamily activate nuclear factor of kappa light polypeptide gene enhancer in B-cells (NF- $\mathrm{BB}$ ), which suppresses apoptosis, cell survival and proliferation (24-26). The regulation of cell growth and activation of NF- $\kappa B$ by the TNF family is mediated by the sequential activation of a set of cell signaling proteins, namely TNF receptor-associated factors, Fas-associated death domain and FADD-like ICE, caspases, receptor interacting proteins, $\mathrm{NF}-\kappa \mathrm{B}$-inducing kinases and I $\kappa \mathrm{B} \alpha$ kinases (27). The intrinsic mitochondrial pathway is controlled by interactions between anti- and pro-apoptotic B-cell lymphoma 2 (Bcl-2) members which share homology via BH3 domains (28). The Bcl-2 family of proteins can be divided into two subgroups: anti-apoptotic proteins, namely $\mathrm{Bcl}-2$, Bcl-xL, Bcl-w, Mcl-1 (myeloid cell leukemia 1), A1, and pro-apoptotic proteins. The pro-apoptotic proteins can be further divided into two classes: i) the Bax-like proteins (Bax, Bak, Bok) and ii) the BH3-only proteins (Bid, Bad, Bim, Bik, Blk, Hrk, Noxa, PUMA) that are unrelated in their sequence to each other or other Bcl-2 family members with the exception of the BH3 domain $(23,29,30)$. While anti-apoptotic members stabilize mitochondrial membrane potential and prevent the release of cytochrome $c$ and apoptosis-inducing factors, pro-apoptotic members activate programmed apoptotic cell death (26,31-33). Anti-apoptotic family members share up to four highly conserved Bcl-2 homology domains, i.e., BH1, BH2, BH3 and BH4 $(23,29,34)$. The multidomain pro-apoptotic Bcl-2 family proteins Bax and Bak are essential for mitochondrial apoptosis; their activity is controlled by the BH3-only pro-apoptotic Bcl-2 family of proteins (28). BH3-only Bcl-2 family members are critical for cell death initiation, can function as tumor suppressors and their loss can induce apoptosis. Their activity is tightly controlled by diverse transcriptional and post-translational mechanisms. BH3-only proteins selectively bind to the hydrophobic groove of anti-apoptotic Bcl-2 family members, leading to Bax/Bak activation (31). Activation of Bax and Bak results in the release of apoptogens from the mitochondrial intermembrane space and activation of an amplifying cascade of caspase-mediated proteolysis $(35,36)$. The release of cytochrome $c$ into the cytoplasm with the involvement of apoptotic peptidase activating factor 1 (APAF1) and deoxy-ATP results in the formation of the apoptosome, which stimulates caspases, a family of apoptosis-related cysteine proteases $(37,38)$. Caspases that initiate cell death and play critical roles in human cell apoptosis are divided into two classes, (i) initiator caspases, i.e., caspase-1, $-2,-4,-5,-8,-9,-10,-12$ and -13 and (ii) the effector caspases, i.e., caspase- $3,-6$ and $-7(26,36)$.

One of the cardinal features of cancer is the deregulation of apoptosis (39). Most drugs, including cancer chemotherapeutic agents, chemicals or irradiation, induce apoptosis by activating the intrinsic apoptotic pathway. High levels of anti-apoptotic Bcl-2 family members are associated with the resistance of many tumor types to clinically used chemotherapy. Apoptosis inhibitors bind selectively to specific types of anti-apoptotic proteins and are useful tools in mechanistic studies $(34,40)$. Over the last few years, several small BH3 mimetic molecules have been synthesized that can inhibit the anti-apoptotic Bcl-2 family of proteins and thus induce apoptosis (41-44).

The most potent small molecule inhibitors are the Bad-like BH3 mimetic ABT-737 and its orally active analog ABT-263, which bind with very high nanomolar affinity to the hydrophobic pocket of the Bcl-2, Bcl-xL and Bcl-w anti-apoptotic proteins $(41,43,45)$. Bcl-2 is expressed in the nervous system, and its function in neuronal tumors was first described by Reed et al (46). Increased expression of Bcl-xL has been found in many solid tumors, including neuronal tumors (18). ABT-737 releases pro-apoptotic proteins that activate Bax and Bak and thus is able to induce apoptosis or sensitize cancer cells to cytotoxic agents in a range of tumor types $(34,43)$. The apoptosis inhibitor ABT-737 does not directly initiate the apoptotic process, but enhances the effect of death signals by selectively binding with a high affinity directly to the hydrophobic areas in the structure of the anti-apoptotic proteins Bcl-2, Bcl-xL, Bcl-w, leading to their inhibition $(19,43)$.

ABT-737 could be an important anticancer agent as it functions by regulating gene transcription and sensitizing resistant tumor types to alternative therapies (47). It displays synergistic cytotoxicity with chemotherapeutics and radiation (43). ABT-737 treatment regulates changes in the transcription of genes involved in cellular senescence (48). As one of the most specific BH3-mimetic agents, ABT-737 can be useful, but also 
ineffective at inducing apoptosis in solid tumors. It targets Bcl-2, Bcl-xL and Bcl-w, but not Mcl-1, and thus tumor cell expression of Mcl-1 is associated with resistance to ABT-737. The control of Mcl-1 has become an area of intense investigation $(32,49,50)$. Resistance to apoptosis is in part mediated by the increased expression of Mcl-1 or Bcl2A1, which are not capable of binding this compound.

The anti-apoptotic protein Mcl-1 was identified as an early response gene induced during the differentiation of human myeloblastic leukemia cells (51) and has been shown to be expressed at relatively high levels in a wide range of hematological as well as solid malignancies (31). Mcl-1 is the most labile anti-apoptotic Bcl-2 protein with a very short half-life. Furthermore, Mcl-1 has been identified in several studies as being the major resistance factor for ABT-737. Destabilization of Mcl-1 makes such cells sensitive to apoptosis-induction by ABT-737 $(32,50,52)$. MIM-1 is a novel molecule that selectively targets the $\mathrm{BH} 3$ binding groove of $\mathrm{Mcl}-1$, with Bak-dependent apoptotic activity (42). It has the opposite biochemical and cellular activity profile of ABT-737 and may have limited cell-type dependent potency. MIM-1 may serve as a prototype for the development of the next generation of small molecules that effectively reduce the apoptotic threshold in cancers specifically driven by anti-apoptotic Mcl-1 protein expression (42). The inhibition of Mcl-1 leads to the inhibition of cell proliferation and metastasis. Hence, it is a promising target for tumor therapy (53).

In our previous studies, we focused on gene expression profiling in different types of healthy and tumor tissues $(54,55)$ as well as GB tissue (56). Genomic characterization can rapidly expand knowledge of the molecular basis of GB $(57,58)$. We hypothesized that deregulation of the apoptotic pathway in astrocyte and GB cells after selective apoptosis inhibitor treatment may contribute to understanding brain tumor cell metabolism and the process of tumor formation.

\section{Materials and methods}

Cell lines and culture conditions. The human astrocyte cell line (HA) was purchased from ScienCell Research Laboratories (Carlsbad, CA USA). Cells were cultivated in 96\% (v/v) Astrocyte Medium supplemented with 2\% (v/v) fetal bovine serum (FBS), 1\% (v/v) Astrocyte Growth Supplement and $1 \%(\mathrm{v} / \mathrm{v})$ penicillin/streptomycin solution (all from ScienCell Research Laboratories) and incubated in a humidified atmosphere with $5 \% \mathrm{CO}_{2}$ at $37^{\circ} \mathrm{C}$. The culture medium was renewed every third day. The human GB cell line (T98G) was purchased from the European Collection of Cell Cultures (Salisbury, UK). Cells were cultivated in 89\% (v/v) Dulbecco's modified Eagle's medium (PAA, Linz, Austria) supplemented with $10 \%$ (v/v) FBS (Gibco, USA), $1 \%(\mathrm{v} / \mathrm{v})$ penicillin/streptomycin solution (PAA) and incubated in a humidified atmosphere with $5 \% \mathrm{CO}_{2}$ at $37^{\circ} \mathrm{C}$. The culture medium was renewed every third day.

Drug treatment. The $\mathrm{IC}_{50}$ value, defined as the concentration that reduces the global growth of cells by $50 \%$, was determined for the apoptosis inhibitors ABT-737 and MIM-1, individually, for the HA and GB (T98G) cell lines. The apoptosis inhibitor concentrations and treatment time periods were selected experimentally according to preliminary experiments. The final ABT-737 treatment was performed with 10 -fold increasing concentrations in the range of 0.001-100 $\mu \mathrm{mol} / 1$, and the final MIM-1 treatment was performed with 4-fold increasing concentrations in the range of $0.4-400 \mu \mathrm{mol} / 1$, for $48 \mathrm{~h}$.

Cell viability assay. The biochemical colorimetric 3-(4,5-dimethylthiazol-2-yl)-2,5-diphenyltetrayolium bromide (MTT) assay, based on the enzymatic conversion of MTT to a violet formazan salt (59), was used to assess the viability of the HA and T98G cells. Briefly, the cells in culture medium were seeded $\left(3.5 \times 10^{3}\right.$ cells $/$ well for the HA cell line, $3.0 \times 10^{3}$ cells/well for T98G cell line) in 96-well microtiter plates. On the third day, the medium was changed to culture medium supplemented with the apoptosis inhibitor ABT-737 (Abbott, USA) or MIM-1 (Calbiochem, Billerica, MA, USA) at varied concentrations and incubation continued for another two days. After the treatment with the apoptosis inhibitors, cells were rinsed once with Dulbecco's phosphate buffer saline (DPBS) and further incubated in medium supplemented with $0.5 \mathrm{mg} / \mathrm{ml}$ MTT in a humidified atmosphere for $6 \mathrm{~h}$. During a subsequent incubation for $16 \mathrm{~h}$ in medium containing SDS [5\% (w/v)], the precipitated formazan, the amount of which is proportional to the number of live cells, was solubilized. The absorbance of the formazancontaining solution was measured at $540 \mathrm{~nm}$ using an ELISA plate reader (Bio-Rad PR2100; Bio-Rad Laboratories, Inc., Hercules, CA, USA). The absorbance was also determined for the medium of the control cells not exposed to the apoptosis inhibitors. The percentage of cell viability was calculated relative to the untreated control cells. The $\mathrm{IC}_{50}$ values were determined for both human brain cell lines after individual apoptosis inhibitor treatment.

RNA extraction and reverse transcription. Total RNA was extracted from the HA and T98G cell lines after $48 \mathrm{~h}$ of apoptosis inhibitor treatment (individually) at the $\mathrm{IC}_{50}$ with TRI Reagent ${ }^{\circledR}$ (MRC, Cincinnati, OH, USA) following the manufacturer's protocol. The RNA quality of each sample was checked using a NanoDrop ${ }^{\circledR}$ apparatus (Thermo Fisher Scientific Inc., Wilmington, DE, USA) and by $\mathrm{MCE}^{\circledR}-202$ MultiNA (Shimadzu Corporation, Kyoto, Japan). Five micrograms of total RNA were reverse transcribed in a total volume of $14 \mu 1$ using the Maxima First Strand cDNA Synthesis kit (Thermo Scientific, USA) according to the manufacturer's protocol.

TaqMan gene expression array. The regulation of gene expression was studied using TaqMan ${ }^{\circledR}$ Human Apoptosis Array (Applied Biosystems ${ }^{\mathrm{TM}}$, USA) based on the qRT-PCR reaction. The predesigned 384-well microfluidic card contained 93 human apoptotic genes and three endogenous control genes: eukaryotic 18S rRNA (18S), $\beta$-actin (ACTB) and glyceraldehyde-3-phosphate dehydrogenase (GAPDH). A reaction mixture with $100 \mathrm{ng}$ cDNA template and an equal volume of the TaqMan ${ }^{\circledR}$ Gene Expression Master Mix was loaded into each line of the microfluidic card. The PCR mix (2x100 $\mu \mathrm{l})$ was distributed into the wells by two centrifugations at $450 \mathrm{x}$ g for $1 \mathrm{~min}$, sealed and loaded into the ViiA7 RealTime PCR system (Applied Biosystems Life Technologies, 
Foster City, CA, USA). The standard amplification protocol consisted of a ramp of $50^{\circ} \mathrm{C}$ for $2 \mathrm{~min}$ and a hot start of $94.5^{\circ} \mathrm{C}$ for $10 \mathrm{~min}$, followed by 40 cycles of $15 \mathrm{sec}$ at $95.0^{\circ} \mathrm{C}$ and 60 $\mathrm{sec}$ at $60.0^{\circ} \mathrm{C}$. Samples were measured in duplicate and the levels of the genes of interest were normalized to the three endogenous controls (18S, ACTB, GAPDH), determined using the $\Delta \Delta \mathrm{Ct}$ method. The expression data from the untreated cells were used as a reference in the $\Delta \Delta \mathrm{Ct}$ method calculation for each cell line individually. The levels of the genes were considered to be significant when their average fold change (FC) was $\leq-2.0$ or $\geq 2.0$.

\section{Results}

Sensitivity of the cell lines to apoptosis inhibitor treatment. To estimate the sensitivity of HA and T98G cells to the apoptosis inhibitors ABT-737 and MIM-1, the colorimetric MTT assay was used to detect cell viability and to determine the $\mathrm{IC}_{50}$ value. The astrocyte and GB cell lines demonstrated different sensitivities to the inhibitors after $48 \mathrm{~h}$ (Fig. 1). The $\mathrm{IC}_{50}$ value of the astrocyte cell line HA was 4-fold lower $(0.85 \mu \mathrm{mol} / \mathrm{l})$ compared with the $\mathrm{IC}_{50}$ of the GB cell line T98G $(3.40 \mu \mathrm{mol} / \mathrm{l})$ after ABT-737 inhibitor treatment (Fig. 1A). The $\mathrm{IC}_{50}$ value of the HA cell line was almost 5 -fold lower $(16.10 \mu \mathrm{mol} / \mathrm{l})$ compared with the $\mathrm{IC}_{50}$ of the T98G cell line $(80.20 \mu \mathrm{mol} / \mathrm{l})$ after MIM-1 inhibitor treatment (Fig. 1B). The viability of the GB cells refers to their relative resistance to the apoptosis inhibitors compared to the astrocyte cell line.

Effect of apoptosis inhibitors on the expression of apoptosis-associated genes. The expression levels of 93 apoptosis-associated genes were studied in the astrocyte and GB cell lines after $48 \mathrm{~h}$ of apoptosis-inhibitor treatment (individually) at the $\mathrm{IC}_{50}$ using an intact cell line as a reference. The pre-designed TaqMan ${ }^{\circledR}$ Human Apoptosis Array Micro Fluidic Cards (Applied Biosystems Life Technologies) contain the most important apoptosis signaling pathway-related genes and three internal controls (18S, ACTB, GAPDH) for data normalization.

\section{HA cell line and MIM-1 treatment}

Bcl-2 family regulated pathway. The expression patterns of the apoptotic genes were significantly different in the astrocyte cell line HA after treatment with the apoptosis inhibitor MIM-1 compared to the reference untreated HA cell line (Fig. 2). The significantly higher expression of $\mathrm{Bcl}-2$ (FC, 4.43) and Bcl-w (FC, 3.93) may serve as a protective factor against apoptosis in astrocytes. Other upregulated genes included the apoptosis facilitator Bim (FC, 11.77), which plays an important role in neuronal apoptosis and can be induced by nerve growth factor, as well as upregulation of the pro-apoptotic genes PUMA (FC, 13.12), Bad (FC, 2.86), Bax (FC, 2.70), NOXA (FC, 2.59), BCL2L13 (FC, 4.42), BNIP3 (FC, 5.86) and BNIP3L (FC, 6.09). The most significant genes associated with apoptosis, Bax and Bcl-2, were both upregulated, but upregulation of $\mathrm{Bcl}-2$ was markedly higher ( $\mathrm{FC}$ of 4.43 compared to 2.70).

TNF receptor pathway. The astrocyte cell line HA demonstrated altered regulation of the TNF receptor pathway after treatment with the apoptosis inhibitor MIM-1 (Fig. 3).
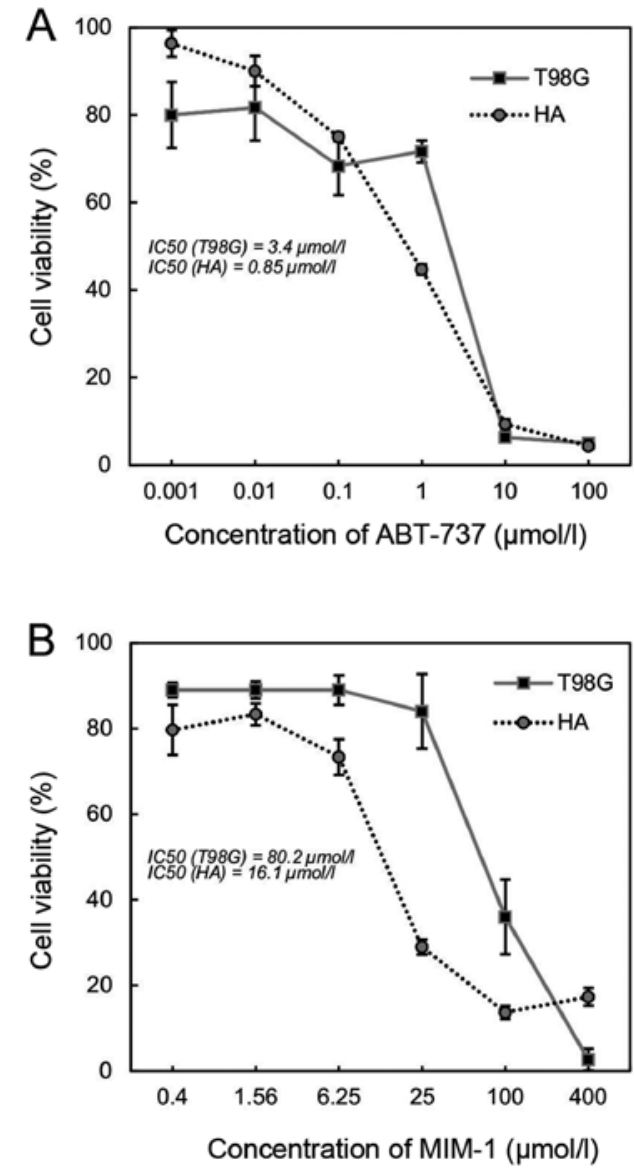

Figure 1. Viability of the cell lines HA and T98G after $48 \mathrm{~h}$ of treatment with an apoptosis inhibitor: (A) ABT-737 or (B) MIM-1.

The most pronounced changes were significant decreased expression of the genes TNFSF10 (TRAIL) (FC, -17.02) and TNFRSF1B (FC, -4.22) and increased expression of TNFRSF10B (FC, 7.46), LRDD (FC, 4.36) and CASP8AP2 (FC, 3.50). Slight upregulation was detected in the genes CRADD, RIPK1, RIPK2, TNFRSF1A, TNFRSF10A and TRADD.

Caspases. Our results showed pronounced significantly increased expression of the inflammatory caspase CASP5 (FC, 16.14) as well as upregulation of the associated caspase CASP4 (FC, 4.13), but there did not seem to be an important causative role of CASP8 activation (FC, -3.88), which was downregulated (Fig. 3).

$N F-\kappa B$ signaling pathway. Genetic analysis revealed significant upregulation of RELB (FC, 8.88), RELA (FC, 5.55), REL (FC, 3.39), NFKBIB (FC, 4.96) and TBK1 (FC, 4.78) and slight upregulation of CHUK, IKBKG, NFKB2, NFKBIA, NFKBIE and NFKBIZ in the NF- $\kappa B$ signaling pathway (Fig. 3).

Inhibitor of apoptosis (IAP) family. Baculoviral IAP repeat-containing (BIRC) proteins are members of the IAP gene family which encode for proteins that prevent apoptotic cell death (60-62). Significantly increased expression of the gene BIRC4 (FC, 2.60) was observed (Fig. 3).

Caspase activation and recruitment domain (CARD) family. CARDs are interaction motifs found in a wide array of proteins, typically those involved in apoptosis (63-66). In the 

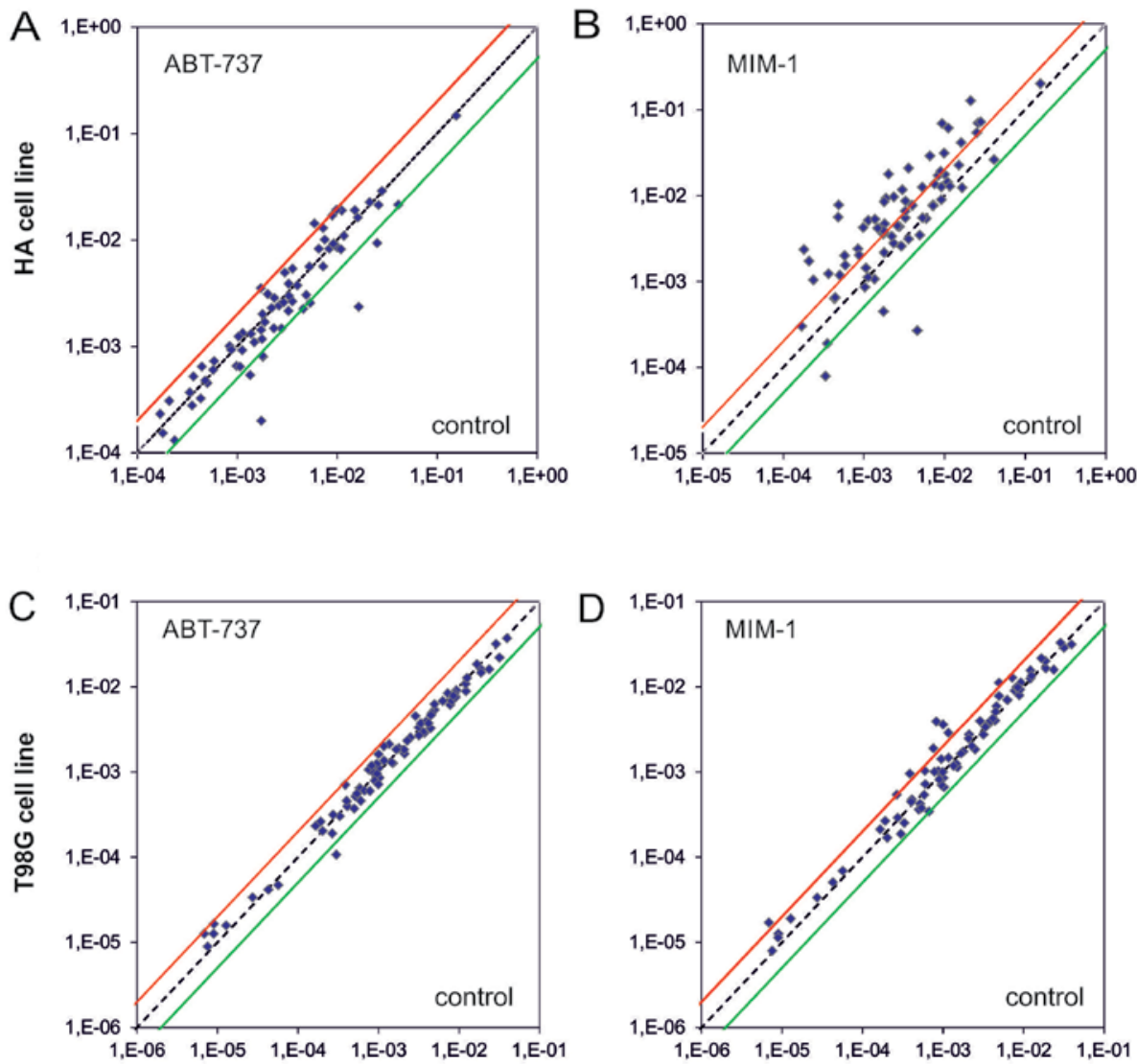

Figure 2. Scatter plot of individual apoptosis-related gene expression in both brain cell lines: (A and B) HA and (C and D) T98G, between the intact control and the inhibitor (A and C) ABT-737- and (B and D) MIM-1-treated cells. Overexpressed genes are located above the red line, underexpressed genes are located below the green line.

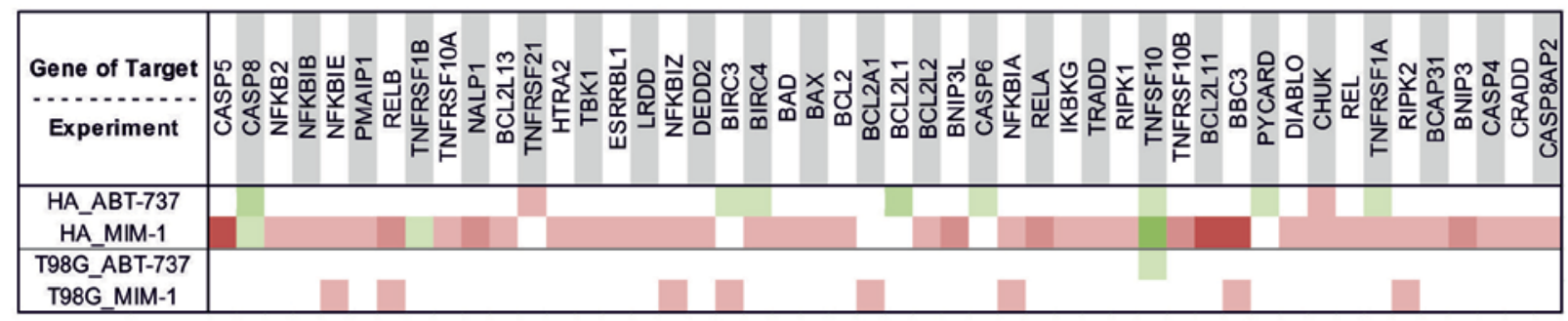

\begin{tabular}{|llllll|}
\hline & & & & \\
\hline$-10.0<$ & $-5.0<\quad-2.0 \leq$ & FC not detected & $\geq 2.0 \quad>5.0$ & $>10.0$
\end{tabular}

Figure 3. Scale of differentially expressed genes in the glioblastoma and astrocyte cell lines after individual treatment with the apoptosis inhibitors ABT-737 or MIM-1. Colors depict high (red) and low (green) relative expression to the intact control used as a reference.

astrocyte cell line, MIM-1 treatment significantly upregulated NALP1 expression (FC, 8.30) (Fig. 3).

Changes observed in the expression of other genes. There was a significant increase in the expression of HTRA2, DEDD2, DIABLO, BCAP31 and ESRRBL1 (Fig. 3).

HA cell line and ABT-737 treatment. The expression patterns of apoptotic genes were significantly different for only 10 apoptosis-associated genes, involved in different regulatory pathways, in the astrocyte cell line HA after treatment with the apoptosis inhibitor ABT-737 compared to the reference, untreated HA cell line (Fig. 3). Significantly lower expression was detected for the genes BCL2L1 (FC, -6.95), TNFRSF1A (FC, -2.68), TNFSF10 (FC, -2.03), CASP8 (FC, -8.63), CASP6 (FC, -2.08), BIRC3 (FC, -2.50), BIRC4 (FC, -2.26) and PYCARD (FC, -2.17), while expression of the genes TNFRSF21 (FC, 2.42) and CHUK (FC, 2.06) was significantly higher.

Human GB cell line and MIM-1 treatment. The expression patterns of apoptotic genes were significantly different for only eight apoptosis-associated genes in the GB cell line 
T98G after treatment with the apoptosis inhibitor MIM-1 compared to the reference, untreated T98G cell line (Fig. 3). Genes with prominently altered expression are involved in different regulated pathways, most of them $(n=4)$ in the $\mathrm{NF}-\kappa \mathrm{B}$ signaling pathway. Significantly higher expression was observed for the genes BBC3 (FC, 2.04), BCL2A1 (FC, 2.50), NFKBIA (FC, 2.26), NFKBIE (FC, 2.50), NFKBIZ (FC, 4.79), RELB (FC, 2.51), RIPK2 (FC, 2.49) and BIRC3 (FC, 3.62).

Human GB cell line and ABT-737 treatment. A difference in in the expression of only one apoptotic gene was observed in the panel of apoptosis-associated genes in the GB cell line T98G after treatment with the apoptosis inhibitor ABT-737 compared to intact T98G cells (Fig. 3). Significantly lower expression was observed for the gene TNFSF10 (FC, -2.78), which is involved in the TNF receptor regulated pathway.

\section{Discussion}

Brain tumors are very diverse in their biological behavior and therefore are considered a major issue in modern medicine. GB, WHO grade IV, arises from astrocytes de novo as primary GB or by malignant transformation of lower grade astrocytomas as secondary GB. Generally, GB is the most aggressive brain tumor in adulthood and is often resistant to clinical treatment. Searching for new markers and treatment targets is the aim of current research studies $(3,11)$. Notably, human malignant gliomas exhibit high Bcl-2 protein levels, and glioma cells with stem cell features are characterized by high expression of Mcl-1 (67). Therefore, targeting these proteins in human GB and astrocytes may contribute to understanding the process of apoptotic cell death in this aggressive brain tumor.

The aim of our study was to assess the sensitivity of astrocyte and GB cells to apoptosis inhibitors (ABT-737 and MIM-1) by the colorimetric MTT assay (Fig. 1) and to analyze apoptotic gene expression changes after apoptosis inhibitor treatment (Figs. 2 and 3) using the commercially available set of genes included in the TaqMan ${ }^{\circledR}$ Human Apoptosis Array Microarray Card. Cell sensitivity to apoptosis inhibitors depends on the expression levels of appropriately inhibited anti-apoptotic proteins. Based on the cell viability results and $\mathrm{IC}_{50}$ values, GB cells express higher levels of Bcl-2, Bcl-xL, Bcl-w and Mcl-1 proteins compared to astrocytes. The results of our study demonstrate the relative resistance of the GB cell line T98G to apoptosis inhibitors compared to the astrocyte cell line HA and show that the expression patterns of several apoptotic genes are significantly different between the cell lines after individual apoptosis inhibitor treatment against the appropriate untreated cell line as a reference (Fig. 2). Our understanding all the biological attributes and molecular phenotypes of astrocytes and GB cells is still limited and remains one of the most challenging investigations worldwide. Sensitivity determination in the HA and T98G cell lines to selective apoptosis inhibitors and the characterization of gene expression signatures can help to us understand the mechanism of GB malignant transformation and increase our knowledge about GB physiology.

The development of Bcl-2 inhibitors with the ability to specifically inhibit $\mathrm{BH} 3-\mathrm{Bcl}-2$ family member protein-protein interactions at low nanomolar concentrations with no toxicity is potentially a significant development in cancer therapy. The great challenge now is to explore how to best utilize these compounds in different tumor types. The Bcl-2 family of protein inhibitors represent a promising avenue of anticancer therapy, either to be used as single agents, or they may be very beneficial in combination with other modalities $(32,41)$. ABT-737 potentiates the cytotoxicity of the chemotherapeutic drugs vincristine and etoposide, and the inhibition of proliferation and the induction of apoptosis by ABT-737 are less efficient in glioma stem cells than in non-stem cell-like glioma cells. The resistance of glioma stem cells is associated with high Mcl-1 expression levels (67). The combination of ABT-737 and MIM-1 results in synergistic cytotoxicity (42). Therefore, the identification of cell sensitivity and gene alterations in tumor and normal brain cells after specific apoptotic pathway inhibition may lead to important knowledge and help in the development of significant therapeutic advances. In the present study, the astrocyte and GB cell lines demonstrated different sensitivity to individual ABT-737 and MIM-1 inhibitor treatment, and allowed us to identify the $\mathrm{IC}_{50}$ values. According to our results (Fig. 1), the $\mathrm{IC}_{50}$ value of the astrocyte cell line $\mathrm{HA}$ was 4-fold lower compared with the $\mathrm{IC}_{50}$ of the $\mathrm{GB}$ cell line T98G after ABT-737 treatment. Similarly, with MIM-1 inhibitor treatment, the astrocyte cell line HA was more sensitive with an $\mathrm{IC}_{50}$ value almost 5-fold lower compared with the $\mathrm{IC}_{50}$ value of the GB cell line T98G. The viability of GB cells was in reference to the relative resistance of the astrocyte cell line to apoptosis inhibitors.

Many recent studies have analyzed and confirmed changes in p53 gene expression in human tumor tissue or cell lines. Higher expression of this gene is associated with the activation of programmed apoptotic cell death (68-71). One possible reason of differentially expressed apoptotic genes is that studied cell lines have different p53 status (p53 is a tumor suppressor protein that regulates the expression of a wide variety of genes involved in apoptosis), because normal HAs are wild-type and the T98G cell line is mutated. Therefore, alterations in apoptosis pathways are considered to play a key role in tumor formation and progression. Tumorigenesis can be driven by the deregulation and perturbation of apoptotic cell death pathways and represents one of the major reasons for the failure of conventional anticancer treatment in the clinic $(31,41,72)$. GB cells show globally lower expression of caspase-3, compared to the expression of the $\mathrm{Bcl}-2$ protein, suggesting that anti-apoptotic mechanisms in tumor cells are more active than pro-apoptotic pathways (9). Highly invasive cancer cells are protected from apoptosis by the upregulation of various anti-apoptotic molecules, including Bcl-2. Human malignant GB cells also present high levels of the Bcl-2, which may confer resistance to apoptosis $(9,67)$. Overexpression of Bcl-2 provides a survival advantage to cancer cells in response to a wide range of apoptotic stimuli through the inhibition of mitochondrial cytochrome $c$ release (26). Inhibition of Mcl-1 is associated with synergistic upregulation of Bim by the displacement of Bak from Mcl-1 (73). Moreover, blocking Mcl-1-mediated suppression of Bid-induced Bax activation in vitro can activate cell death pathways (42). Our results showed that normal HAs showed upregulated expression of Bim by $>11$-fold and Bax by $>2$-fold after Mcl-1 inhibition by MIM-1. The potential function of Bcl-2 in neuronal cells was 
first described by Reed et al (46). Bcl-2 is therefore considered to be a predominant anti-apoptotic protein that preserves neuronal cell survival. Consistent with these findings, our results showed upregulation of Bcl-2 and Bcl-w in the normal HA cell line, which may serve as an essential protective factor against apoptosis after Mcl-1 inhibition by MIM-1 .

BH3-only proteins are essential initiators of apoptosis signaling, including Bcl-2-binding component 3 (BBC3) or also a p53 upregulated modulator of apoptosis (PUMA), which is a pro-apoptotic member of the BH3-only subgroup of the Bcl-2 family (31). Biochemical studies have shown that PUMA interacts with anti-apoptotic Bcl-2 family members such as Bcl-xL, Bcl-2, Mcl-1, Bcl-w, BCL2A1 and inhibits their interaction with the pro-apoptotic molecules, Bax and Bak (74). A subsequent study demonstrated that PUMA was able to induce apoptosis of glioma cells and overexpression of PUMA induces activation of caspases and cytochrome $c$ release (75). We obtained results of PUMA upregulation after MIM-1 inhibitor treatment; p53-wild type astrocyte cell line HA exhibited PUMA expression several-fold higher compared to the GB p53-mutated (T98G) cell line.

The protein Diablo acts as an IAP antagonist (24), but its slight upregulation after MIM-1 treatment in astrocytes did not cause changes in IAP family expression (except for the upregulation of BIRC4). According to our previous results (56), we detected in human GB biopsy tissue a pronounced significant increase in the gene coding neuronal apoptosis inhibitory protein BIRC1 (NAIP). The protein BIRC1 prevents neuronal apoptosis induced by a variety of signals and enhances neuronal survival under pathological conditions (76-78). We did not observe changes in BIRC1 gene expression after ABT-737 or MIM-1 inhibitor treatment in the GB cell line.

Caspase activity is regulated by certain members of the IAP family, most potently by BIRC4 (XIAP), which is able to bind to and inactivate members of the caspase family of cell death proteases, i.e., caspase- $9,-3$ and -7 (30). BIRC4 functions also by binding to the tumor necrosis factor receptor-associated factors TRAF1 and TRAF2, which form a heterodimeric complex required for the activation of NF- $\mathrm{kB}$. Active NF- $\kappa$ B stimulates the expression of genes that maintain cellular proliferation and protect cells from conditions leading cells to apoptosis. According to our results, slight upregulation of XIAP after MIM-1 treatment in astrocytes was associated with deregulation of the NF- $\kappa B$ signaling pathway. Previous studies have demonstrated that the extrinsic apoptotic pathway is severely inhibited in high-grade gliomas (17,79-81). We observed changes in multiple gene encoding proteins involved in the extrinsic apoptotic pathway in astrocytes, but only several slight expressional changes in genes involved in the extrinsic apoptotic pathway in GB cells after selective intrinsic apoptotic pathway inhibition. The extrinsic apoptotic pathway is triggered by the binding of death ligands of the TNF family to their appropriate death receptors on the cell surface. TNF family members are responsible for the transmission of signals from extracellular death ligands through death receptors to the cell's apoptotic machinery. High levels of Mcl-1 are often associated with resistance to TRAIL (25), although Mcl-1 is involved in the intrinsic mitochondrial pathway and TRAIL plays a role in the extrinsic receptor pathway of apoptotic cell death $(27,31)$. Our results showed a significant decrease, i.e., $>17$-fold, in the expression of TNFSF10 after anti-apoptotic protein Mcl-1 inhibition, which confirms the association between the effectiveness and activation of this protein.

Multiple changes in genes encoding for proteins associated in the TNF and NF- $\mathrm{kB}$ signaling pathways resulted in CASP8 downregulation after treatment with the individual apoptosis inhibitors in the astrocyte cell line. Low endogenous caspase- 8 levels may be responsible for a decrease in the activation of the effector caspase-3 and result in the resistance of cells to death ligands $(79,81)$. The frequent occurrence of low levels of caspase-8 in glioma may complicate the future development of therapies for patients with this malignancy. Our data indicate alterations in various members of the TNF and NF- $\mathrm{KB}$ signaling pathway in astrocytes after Mcl-1 inhibition. We observed cognate results with the downregulation of caspase-8. The extrinsic apoptotic pathway in HA and GB cells has not yet been systematically studied, but previous reports have demonstrated inhibition of the extrinsic pathway in high-grade gliomas $(17,80,81)$. Our experiments showed a significant downregulation in TNFSF10, which may affect formation of death-inducing signaling complex (DISC) (82), and subsequently result in low levels of caspase-8 (81); in keeping with this, our experiments showed significant downregulation of CASP8. These changes may prevent apoptotic cell death via the activation of the extrinsic apoptotic pathway in astrocytes after the inhibition of anti-apoptotic proteins involved in the intrinsic apoptotic pathway and ensure cell survival. On the contrary, our results showed an increase in gene expression of inflammatory caspases- 4 and -5 in the astrocyte cell line after Mcl-1 inhibition, which could be involved in immunoregulation (65).

The development of DNA microarray technologies over the past decade has revolutionized translational cancer research. Over the past decade, tremendous progress has been made in DNA microarray-based gene expression profiling of gliomas. Such progress in this research field may lead to identifying subsets of genes uniquely responsive to specific adjuvant therapies and provide individualized clinical care of glioma patients in the future (57). Targeting apoptotic pathways in selected cell lines offers a unique opportunity to develop novel therapeutic strategies that may overcome tumor resistance. We have shown in our study that HAs are more susceptible to selective apoptosis inhibitors (individually) than GB cells, in which apoptosis-associated gene expression is relatively stable after ABT-737 or MIM-1 treatment. Improved characterization of apoptotic gene expression differences in astrocytes and GB cells may lead to a better understanding of normal and cancerous brain cell metabolism and improve the treatment of brain tumors. Monitoring of differentially expressed human apoptosis-associated genes in cell lines might provide a useful research tool to investigate experimental models of CNS cells. Furthermore, cDNA microarrays may aid in establishing and improving gene expression patterns capable of predicting individual responses to therapy. The results of several recent studies have shown a synergistic effect of apoptosis inhibitors with clinically used cytostatics which enhanced their cytotoxicity $(42,43,73,83)$. The concept is that the combination of apoptotic Bcl-2 inhibitors with a chemotherapeutic agent such as temozolomide, which is routinely used in clinical practice, 
may provide a better clinical effect. This combination may lead to apoptosis if the threshold to undergo apoptosis is sufficiently low. Recognition of all the biological attributes of GB growth inhibition still remains one of the most challenging questions worldwide.

\section{Acknowledgements}

The authors are thankful to Dr Mahmoodova and Dr Murin for donation and preparation of HA cell line for experiments. We appreciate support by the Slovak Research and Development Agency under contract no. APVV-0224-12 and by the project 'Biomedical Center Martin' ITMS: no. 26220220187, which is co-financed from EU sources.

\section{References}

1. Richterová R, Jurečeková J, Evinová A, Kolarovszki B, Benčo M, De Riggo J, Sutovský J, Mahmood S, Račay P and Dobrota D: Most frequent molecular and immunohistochemical markers present in selected types of brain tumors. Gen Physiol Biophys 33: 259-279, 2014

2. Ricard D, Idbaih A, Ducray F, Lahutte M, Hoang-Xuan K and Delattre JY: Primary brain tumours in adults. Lancet 379: 1984-1996, 2012.

3. Louis DN, Ohgaki H, Wiestler OD, Cavenee WK, Burger PC, Jouvet A, Scheithauer BW and Kleihues P: The 2007 WHO classification of tumours of the central nervous system. Acta Neuropathol 114: 97-109, 2007.

4. Ahmed R, Oborski MJ, Hwang M, Lieberman FS and Mountz JM: Malignant gliomas: Current perspectives in diagnosis, treatment, and early response assessment using advanced quantitative imaging methods. Cancer Manag Res 6: 149-170, 2014.

5. Persano L, Rampazzo E, Basso G and Viola G: Glioblastoma cancer stem cells: Role of the microenvironment and therapeutic targeting. Biochem Pharmacol 85: 612-622, 2013.

6. Pointer KB, Clark PA, Zorniak M, Alrfaei BM and Kuo JS: Glioblastoma cancer stem cells: Biomarker and therapeutic advances. Neurochem Int 71: 1-7, 2014.

7. Schonberg DL, Lubelski D, Miller TE and Rich JN: Brain tumor stem cells: Molecular characteristics and their impact on therapy. Mol Aspects Med 39: 82-101, 2014.

8. Jovčevska I, Kočevar N and Komel R: Glioma and glioblastoma - how much do we (not) know? Mol Clin Oncol 1: 935-941, 2013.

9. Tirapelli LF, Bolini PH, Tirapelli DP, Peria FM, Becker AN, Saggioro FP and Carlotti CG Jr: Caspase-3 and Bcl-2 expression in glioblastoma: An immunohistochemical study. Arq Neuropsiquiatr 68: 603-607, 2010.

10. Ohgaki $\mathrm{H}$ and Kleihues P: Genetic alterations and signaling pathways in the evolution of gliomas. Cancer Sci 100: 2235-2241, 2009.

11. Karsy M, Neil JA, Guan J, Mahan MA, Colman H and Jensen RL: A practical review of prognostic correlations of molecular biomarkers in glioblastoma. Neurosurg Focus 38: E4, 2015.

12. Bralten LBC and French PJ: Genetic alterations in glioma. Cancers (Basel) 3: 1129-1140, 2011.

13. Kleihues P, Louis DN, Scheithauer BW, Rorke LB, Reifenberger G, Burger PC and Cavenee WK: The WHO classification of tumors of the nervous system. J Neuropathol Exp Neurol 61: 215-229, 2002.

14. Barazzuol L, Jena R, Burnet NG, Jeynes JC, Merchant MJ, Kirkby KJ and Kirkby NF: In vitro evaluation of combined temozolomide and radiotherapy using Xrays and high-linear energy transfer radiation for glioblastoma. Radiat Res 177: 651-662, 2012.

15. Westhoff MA, Brühl O, Nonnenmacher L, Karpel-Massler G and Debatin KM: Killing me softly-future challenges in apoptosis research. Int J Mol Sci 15: 3746-3767, 2014.

16. Redmond KM, Wilson TR, Johnston PG and Longley DB: Resistance mechanisms to cancer chemotherapy. Front Biosci 13: 5138-5154, 2008.

17. Riffkin CD, Gray AZ, Hawkins CJ, Chow CW and Ashley DM: Ex vivo pediatric brain tumors express Fas (CD95) and FasL (CD95L) and are resistant to apoptosis induction. Neuro Oncol 3: 229-240, 2001.
18. Krajewski S, Krajewska M, Ehrmann J, Sikorska M, Lach B, Chatten J and Reed JC: Immunohistochemical analysis of $\mathrm{Bcl}-2$, Bcl-X, Mcl-1, and Bax in tumors of central and peripheral nervous system origin. Am J Pathol 150: 805-814, 1997.

19. Klymenko T, Brandenburg M, Morrow C, Dive C and Makin G: The novel Bcl-2 inhibitor ABT-737 is more effective in hypoxia and is able to reverse hypoxia-induced drug resistance in neuroblastoma cells. Mol Cancer Ther 10: 2373-2383, 2011.

20. Kögel D, Fulda S and Mittelbronn M: Therapeutic exploitation of apoptosis and autophagy for glioblastoma. Anticancer Agents Med Chem 10: 438-449, 2010.

21. Portt L, Norman G, Clapp C, Greenwood M and Greenwood MT: Anti-apoptosis and cell survival: A review. Biochim Biophys Acta 1813: 238-259, 2011.

22. Fulda S and Debatin KM: Extrinsic versus intrinsic apoptosis pathways in anticancer chemotherapy. Oncogene 25: 4798-4811, 2006.

23. Thomas S, Quinn BA, Das SK, Dash R, Emdad L, Dasgupta S, Wang XY, Dent P, Reed JC, Pellecchia M, et al: Targeting the $\mathrm{Bcl}-2$ family for cancer therapy. Expert Opin Ther Targets 17: 61-75, 2013.

24. Tchoghandjian A, Jennewein C, Eckhardt I, Momma S, FigarellaBranger D and Fulda S: Smac mimetic promotes glioblastoma cancer stem-like cell differentiation by activating NF- $\kappa B$. Cell Death Differ 21: 735-747, 2014.

25. Sayers TJ: Targeting the extrinsic apoptosis signaling pathway for cancer therapy. Cancer Immunol Immunother 60: 1173-1180, 2011.

26. Wong RSY: Apoptosis in cancer: From pathogenesis to treatment. J Exp Clin Cancer Res 30: 87, 2011.

27. Gaur U and Aggarwal BB: Regulation of proliferation, survival and apoptosis by members of the TNF superfamily. Biochem Pharmacol 66: 1403-1408, 2003.

28. Suen DF, Norris KL and Youle RJ: Mitochondrial dynamics and apoptosis. Genes Dev 22: 1577-1590, 2008.

29. Hervouet E, Cheray M, Vallette FM and Cartron PF: DNA methylation and apoptosis resistance in cancer cells. Cells 2: 545-573, 2013.

30. Labi V, Grespi F, Baumgartner F and Villunger A: Targeting the Bcl-2-regulated apoptosis pathway by $\mathrm{BH} 3$ mimetics: A breakthrough in anticancer therapy? Cell Death Differ 15: 977-987, 2008.

31. Kelly PN and Strasser A: The role of Bcl-2 and its pro-survival relatives in tumourigenesis and cancer therapy. Cell Death Differ 18: 1414-1424, 2011.

32. Llambi F and Green DR: Apoptosis and oncogenesis: Give and take in the BCL-2 family. Curr Opin Genet Dev 21: 12-20, 2011.

33. Kim H, Tu HC, Ren D, Takeuchi O, Jeffers JR, Zambetti GP, Hsieh JJ and Cheng EH: Stepwise activation of BAX and BAK by tBID, BIM, and PUMA initiates mitochondrial apoptosis. Mol Cell 36: 487-499, 2009.

34. Vogler M, Dinsdale D, Dyer MJ and Cohen GM: Bcl-2 inhibitors: Small molecules with a big impact on cancer therapy. Cell Death Differ 16: 360-367, 2009.

35. Galluzzi L, Maiuri MC, Vitale I, Zischka H, Castedo M, Zitvogel L and Kroemer G: Cell death modalities: Classification and pathophysiological implications. Cell Death Differ 14: 1237-1243, 2007.

36. Degterev A, Boyce M and Yuan J: A decade of caspases. Oncogene 22: 8543-8567, 2003.

37. Yuan S and Akey CW: Apoptosome structure, assembly, and procaspase activation. Structure 21: 501-515, 2013.

38. Bender A, Opel D, Naumann I, Kappler R, Friedman L, von Schweinitz D, Debatin KM and Fulda S: PI3K inhibitors prime neuroblastoma cells for chemotherapy by shifting the balance towards pro-apoptotic $\mathrm{Bcl}-2$ proteins and enhanced mitochondrial apoptosis. Oncogene 30: 494-503, 2011.

39. Hanahan D and Weinberg RA: Hallmarks of cancer: The next generation. Cell 144: 646-674, 2011.

40. Adams JM and Cory S: The Bcl-2 apoptotic switch in cancer development and therapy. Oncogene 26: 1324-1337, 2007.

41. Vogler M: Targeting BCL2 proteins for the treatment of solid tumours. Adv Med 2014: 943648, 2014.

42. Cohen NA, Stewart ML, Gavathiotis E, Tepper JL, Bruekner SR, Koss B, Opferman JT and Walensky LD: A competitive stapled peptide screen identifies a selective small molecule that overcomes MCL-1-dependent leukemia cell survival. Chem Biol 19: 1175-1186, 2012.

43. Oltersdorf T, Elmore SW, Shoemaker AR, Armstrong RC, Augeri DJ, Belli BA, Bruncko M, Deckwerth TL, Dinges J, Hajduk PJ, et al: An inhibitor of Bcl-2 family proteins induces regression of solid tumours. Nature 435: 677-681, 2005. 
44. Degterev A, Lugovskoy A, Cardone M, Mulley B, Wagner G, Mitchison T and Yuan J: Identification of small-molecule inhibitors of interaction between the $\mathrm{BH} 3$ domain and $\mathrm{Bcl}-\mathrm{xL}$. Nat Cell Biol 3: 173-182, 2001.

45. Tse C, Shoemaker AR, Adickes J, Anderson MG, Chen J, Jin S, Johnson EF, Marsh KC, Mitten MJ, Nimmer P, et al: ABT-263: A potent and orally bioavailable Bcl-2 family inhibitor. Cancer Res 68: 3421-3428, 2008.

46. Reed JC, Meister L, Tanaka S, Cuddy M, Yum S, Geyer C and Pleasure D: Differential expression of bcl2 protooncogene in neuroblastoma and other human tumor cell lines of neural origin. Cancer Res 51: 6529-6538, 1991.

47. Song JH, Kandasamy K, Zemskova M, Lin YW and Kraft AS: The BH3 mimetic ABT-737 induces cancer cell senescence. Cancer Res 71: 506-515, 2011.

48. Cichowski K and Hahn WC: Unexpected pieces to the senescence puzzle. Cell 133: 958-961, 2008.

49. Chen S, Dai Y, Harada H, Dent P and Grant S: Mcl-1 down-regulation potentiates ABT-737 lethality by cooperatively inducing Bak activation and Bax translocation. Cancer Res 67: 782-791, 2007.

50. van Delft MF, Wei AH, Mason KD, Vandenberg CJ, Chen L, Czabotar PE, Willis SN, Scott CL, Day CL, Cory S, et al: The BH3 mimetic ABT-737 targets selective Bcl-2 proteins and efficiently induces apoptosis via Bak/Bax if Mcl-1 is neutralized. Cancer Cell 10: 389-399, 2006.

51. Kozopas KM, Yang T, Buchan HL, Zhou P and Craig RW: MCL1, a gene expressed in programmed myeloid cell differentiation, has sequence similarity to BCL2. Proc Natl Acad Sci USA 90: 3516-3520, 1993.

52. Varin E, Denoyelle C, Brotin E, Meryet-Figuière M, Giffard F, Abeilard E, Goux D, Gauduchon P, Icard P and Poulain L: Downregulation of Bcl- $\mathrm{x}_{\mathrm{L}}$ and $\mathrm{Mcl}-1$ is sufficient to induce cell death in mesothelioma cells highly refractory to conventional chemotherapy. Carcinogenesis 31: 984-993, 2010.

53. Li RY, Chen LC, Zhang HY, Du WZ, Feng Y, Wang HB, Wen JQ, Liu X, Li XF, Sun Y, et al: MiR-139 inhibits Mcl-1 expression and potentiates TMZ-induced apoptosis in glioma. CNS Neurosci Ther 19: 477-483, 2013.

54. Zubor P, Hatok J, Moricova P, Kapustova I, Kajo K, Mendelova A, Sivonova MK and Danko J: Gene expression profiling of histologically normal breast tissue in females with human epidermal growth factor receptor 2 positive breast cancer. Mol Med Rep 11: 1421-1427, 2015.

55. Zubor P, Hatok J, Galo S, Dokus K, Klobusiakova D, Danko J and Racay P: Anti-apoptotic and pro-apoptotic gene expression evaluated from eutopic endometrium in the proliferative phase of the menstrual cycle among women with endometriosis and healthy controls. Eur J Obstet Gynecol Reprod Biol 145: 172-176, 2009.

56. Blahovcova E, Richterova R, Kolarovszki B, Dobrota D, Racay P and Hatok J: Apoptosis-related gene expression in tumor tissue samples obtained from patients diagnosed with glioblastoma multiforme. Int J Mol Med 36: 1677-1684, 2015.

57. Vitucci M, Hayes DN and Miller CR: Gene expression profiling of gliomas: Merging genomic and histopathological classification for personalised therapy. Br J Cancer 104: 545-553, 2011.

58. Cancer Genome Atlas Research Network: Comprehensive genomic characterization defines human glioblastoma genes and core pathways. Nature 455: 1061-1068, 2008.

59. Mosmann T: Rapid colorimetric assay for cellular growth and survival: Application to proliferation and cytotoxicity assays. J Immunol Methods 65: 55-63, 1983.

60. Shiozaki EN and Shi Y: Caspases, IAPs and Smac/DIABLO: Mechanisms from structural biology. Trends Biochem Sci 29: 486-494, 2004.

61. Shi Y: Mechanisms of caspase activation and inhibition during apoptosis. Mol Cell 9: 459-470, 2002.

62. Verhagen AM, Coulson EJ and Vaux DL: Inhibitor of apoptosis proteins and their relatives: IAPs and other BIRPs. Genome Biol 2: REVIEWS3009, 2001.

63. Ouyang L, Shi Z, Zhao S, Wang FT, Zhou TT, Liu B and Bao JK: Programmed cell death pathways in cancer: A review of apoptosis, autophagy and programmed necrosis. Cell Prolif 45: 487-498, 2012
64. Wen X, Lin ZQ, Liu B and Wei YQ: Caspase-mediated programmed cell death pathways as potential therapeutic targets in cancer. Cell Prolif 45: 217-224, 2012.

65. Ghavami S, Hashemi M, Ande SR, Yeganeh B, Xiao W, Eshraghi M, Bus CJ, Kadkhoda K, Wiechec E, Halayko AJ, et al: Apoptosis and cancer: Mutations within caspase genes. J Med Genet 46: 497-510, 2009.

66. Kurokawa $\mathrm{M}$ and Kornbluth S: Caspases and kinases in a death grip. Cell 138: 838-854, 2009.

67. Tagscherer KE, Fassl A, Campos B, Farhadi M, Kraemer A, Böck BC, Macher-Goeppinger S, Radlwimmer B, Wiestler OD, Herold-Mende C, et al: Apoptosis-based treatment of glioblastomas with ABT-737, a novel small molecule inhibitor of Bcl-2 family proteins. Oncogene 27: 6646-6656, 2008.

68. Wei B, Wang L, Du C, Hu G, Wang L, Jin Y and Kong D: Identification of differentially expressed genes regulated by transcription factors in glioblastomas by bioinformatics analysis. Mol Med Rep 11: 2548-2554, 2015.

69. Stancheva G, Goranova T, Laleva M, Kamenova M, Mitkova A, Velinov N, Poptodorov G, Mitev V, Kaneva R and Gabrovsky N: IDH1/IDH2 but not TP53 mutations predict prognosis in Bulgarian glioblastoma patients. BioMed Res Int 2014: 654727, 2014.

70. England B, Huang T and Karsy M: Current understanding of the role and targeting of tumor suppressor p53 in glioblastoma multiforme. Tumour Biol 34: 2063-2074, 2013.

71. Li J: Di Ch, Mattox AK, Wu L and Adamson DC: The future role of personalized medicine in the treatment of glioblastoma multiforme. Pharm Genomics Pers Med 3: 111-127, 2010.

72. Elmore S: Apoptosis: A review of programmed cell death. Toxicol Pathol 35: 495-516, 2007.

73. Song T, Chai G, Liu Y, Xie M, Chen Q, Yu X, Sheng H and Zhang Z: Mechanism of synergy of BH3 mimetics and paclitaxel in chronic myeloid leukemia cells: Mcl-1 inhibition. Eur J Pharm Sci 70: 64-71, 2015.

74. Nakano K and Vousden KH: PUMA, a novel proapoptotic gene, is induced by p53. Mol Cell 7: 683-694, 2001.

75. Ito H, Kanzawa T, Miyoshi T, Hirohata S, Kyo S, Iwamaru A, Aoki H, Kondo Y and Kondo S: Therapeutic efficacy of PUMA for malignant glioma cells regardless of $p 53$ status. Hum Gene Ther 16: 685-698, 2005.

76. Maier JK, Lahoua Z, Gendron NH, Fetni R, Johnston A, Davoodi J, Rasper D, Roy S, Slack RS, Nicholson DW, et al: The neuronal apoptosis inhibitory protein is a direct inhibitor of caspases 3 and 7. J Neurosci 22: 2035-2043, 2002.

77. Holcik M, Thompson CS, Yaraghi Z, Lefebvre CA, MacKenzie AE and Korneluk RG: The hippocampal neurons of neuronal apoptosis inhibitory protein 1 (NAIP1)-deleted mice display increased vulnerability to kainic acid-induced injury. Proc Natl Acad Sci USA 97: 2286-2290, 2000.

78. Mercer EA, Korhonen L, Skoglösa Y, Olsson PA, Kukkonen JP and Lindholm D: NAIP interacts with hippocalcin and protects neurons against calcium-induced cell death through caspase-3-dependent and -independent pathways. EMBO J 19: 3597-3607, 2000.

79. Saggioro FP, Neder L, Stávale JN, Paixão-Becker AN, Malheiros SM, Soares FA, Pittella JE, Matias CC, Colli BO, Carlotti CG Jr, et al: Fas, FasL, and cleaved caspases 8 and 3 in glioblastomas: A tissue microarray-based study. Pathol Res Pract 210: 267-273, 2014.

80. Siegelin MD, Gaiser T and Siegelin Y: The XIAP inhibitor Embelin enhances TRAIL-mediated apoptosis in malignant glioma cells by down-regulation of the short isoform of FLIP. Neurochem Int 55: 423-430, 2009.

81. Ashley DM, Riffkin CD, Muscat AM, Knight MJ, Kaye AH, Novak U and Hawkins CJ: Caspase 8 is absent or low in many ex vivo gliomas. Cancer 104: 1487-1496, 2005.

82. Peter ME and Krammer PH: The CD95(APO-1/Fas) DISC and beyond. Cell Death Differ 10: 26-35, 2003.

83. Konopleva M, Contractor R, Tsao T, Samudio I, Ruvolo PP, Kitada S, Deng X, Zhai D, Shi YX, Sneed T, et al: Mechanisms of apoptosis sensitivity and resistance to the BH3 mimetic ABT-737 in acute myeloid leukemia. Cancer Cell 10: 375-388, 2006. 